\title{
Effect of combination of hydrocolloid and emulsifiers on micro visco - amylograph, physical and storage qualities of eggless cake
}

\author{
A. Ashwini, D. Indrani and H.N. Ramya
}

\begin{abstract}
The present study was aimed to investigate the effect of hydrocolloids like gum arabic (AR), guar gum (GR), xanthan gum $(\mathrm{XN})$, carrageenan (CG) and hydroxypropyl methylcellulose (HPMC) were used in combination with emulsifiers such as glycerol monstearate (GMS) and sodium stearoyl-2-lactylate (SSL) on the physical, sensory and storage characteristics of eggless cake was studied. Addition of hydrocolloids to wheat flour as well as in the presence of GMS and SSL increased the eggless cake batter viscosity, specific gravity; in which XN showed the highest value. Among the different hydrocolloids screened, HPMC improved the eggless cake making characteristics of the wheat flour. The overall quality score of eggless cake was increased with HPMC, GMS and SSL. The results indicate that among hydrocolloids used for the study; HPMC brought about highest improvement in eggless cake making characteristics of wheat flour as well eggless cake with GMS and SSL. Effect of combination of hydrocolloid and emulsifiers on storage characteristics of eggless cake was also studied. The moisture content of control eggless cake was 30.8 per cent and eggless cake with the combination of HPMC, GMS and SSL was 33.48 per cent and the moisture content of eggless cake showed not much change during storage for 10 days. It is clear from the results that the texture values of eggless cake with combination at any time of storage were lower than the control eggless cake.
\end{abstract}

Key Words : Eggless cake, Hydrocolloids, Emulsifiers, Batter viscosity, Texture

How to cite this article : Ashwini, A., Indrani, D. and Ramya, H.N. (2019). Effect of combination of hydrocolloid and emulsifiers on micro visco - amylograph, physical and storage qualities of eggless cake. Food Sci. Res. J., 10(1): 70-80, DOI : 10.15740/HAS/ FSRJ/10.1/70-80. Copyright@ 2019: Hind Agri-Horticultural Society.

Author for correspondence :

A. Ashwini, Department of Food Science and Technology, Agricultural

College, Hassan (Karnataka) India

(Email : ashwinicftri@gmail.com)

\section{Associate Authors'}

D. Indrani, Department of Flour Milling, Baking and Confectionery Technology, CSIR-Central Food Technological Research Institute, Mysore (Karnataka) India

H.N. Ramya, Department of Food Science and Technology, Agricultural College, Hassan (Karnataka) India 